\title{
Simulating the large-scale spatial sand-mud distribution in a schematized process-based tidal inlet system model
}

\author{
F. Scheel ${ }^{1,2,3}$, M. van Ledden ${ }^{1,2}$, B.C. van Prooijen ${ }^{1}$ and M.J.F. Stive ${ }^{1}$ \\ ${ }^{1}$ Faculty of Civil Engineering \& Geosciences, section Hydraulic Engineering, Delft University of Technology, $2628 \mathrm{CN}$, Delft, The \\ Netherlands, f.scheel@me.com \\ ${ }^{2}$ Business Line Water, Royal Haskoning, George Hintzenweg 85, 3068 AX, Rotterdam, The Netherlands, \\ m.vanledden@royalhaskoning.com \\ ${ }^{3}$ Sea and Coastal Systems, Unit Morphology and Sedimental Systems, Deltares, 2629 HD, Delft, The Netherlands, info@deltares.nl
}

\begin{abstract}
Tidal basins, as found in the Dutch Wadden Sea, are characterized by strong spatial variations in bathymetry and sediment distribution. In this contribution, the aim is at simulating the spatial sand-mud distribution of a tidal basin. Predicting this spatial distribution is however complicated, due to the non-linear interactions between tides, waves, sediment transport, morphology and biology. To reduce complexity, while increasing physical understanding, an idealized schematization of the Amelander inlet system is considered. Delft3D is applied with a recently developed bed module, containing various sediment layers, combined with formulations for both cohesive and non-cohesive sediment mixtures. Starting with uniform mud content in the spatial domain, the development of the sediment distribution is simulated. Realistic sand-mud patterns are found, with accumulation of mud on the tidal flats. The schematization is further used to determine the sensitivity of the sand-mud patterns to changes in tide, while assessing the influence of tidal dominance on the large-scale sand-mud patterns. The patterns are enhanced/diminished under the influence of higher/lower tides.
\end{abstract}

\section{INTRODUCTION}

Silt and clay particles are present in many tidal basins around the world. Together with sand, these particles often form the total sediment distribution within these systems.

Silt and clay particles (further referred to as mud) respond different to forcing (like waves and currents), compared to sand particles. This results in spatial sand-mud segregation. The differences in settling velocity and critical shear stresses of mud (mixtures), compared to sand, are mainly responsible for this different behavior and response.

The spatial sand-mud segregation patterns are very pronounced in the tidal inlet systems of the Dutch Wadden Sea. When mud particles are available, they tend to settle in less hydrodynamic active areas, like tidal flats. Van Straaten and Kuenen [1957] described this behavior in the former Lauwerszee, using Figure 1.

Many morphodynamic researches are aimed at predicting (modelling) the morphological evolution. A 'sand-only' model is often justified here, as sand is by far the main contributor to the morphological evolution in many cases. However, mud particles can have a significant local contribution on morphology, as it gets transported to distinct areas (as supported by Figure 1). Furthermore, the spatial distribution of flora and fauna is highly correlated to the spatial sand-mud distribution, as various species require a certain sand- or mud content to grow/live. Finally, cohesive mud particles tend to attract pollutants. The spatial mud content is therefore an important indicator for the degree of potential pollution.

Assessment of the above mud-related topics, requires prediction (modelling/simulation) of the spatial sand-mud distribution, for instance in a tidal inlet system in the Dutch Wadden Sea. However, this assessment involves non-linear interactions between tides, waves, sediment transport, morphology and biology. This makes it a challenging task.

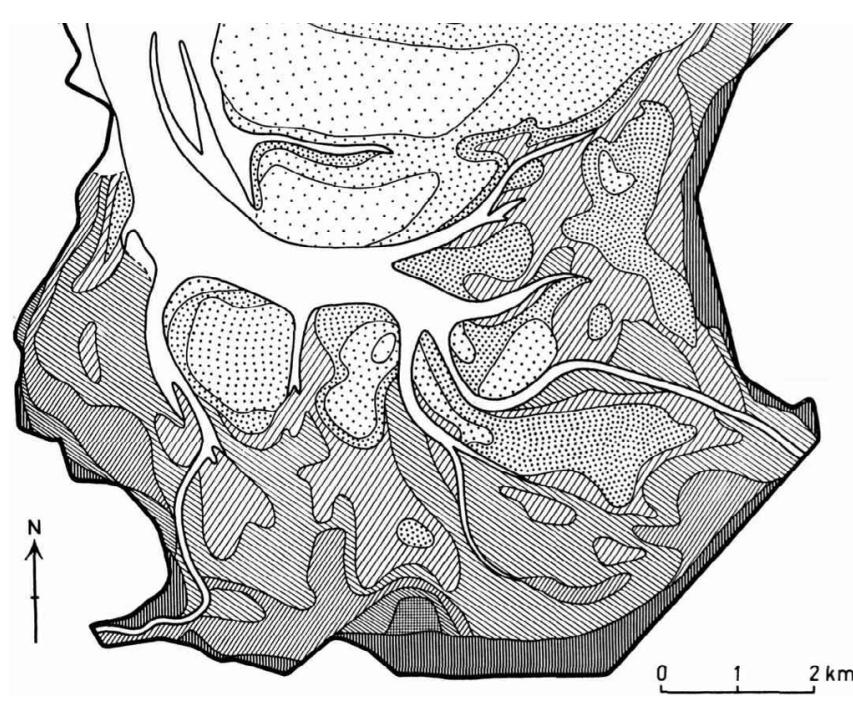

Figure 1. Clay content distribution in the former Lauwerszee, near the current Dutch Wadden Sea, increasing from $0 \%$ (white) to $>25 \%$ (dark grey) clay content [Van Straaten \& Kuenen, 1957]

Recent research [Van Ledden, 2003] provides us with a tool to model the sand-mud segregation patterns more effectively. While Van Ledden et al. [2004] found insightful results in various 1D models, a 3D model of the Friesche Zeegat [Van Ledden, 2003] resulted in both similarities and discrepancies compared to reality. But even more important, the physical understanding of the 3D model diminished, mainly due to the complex bathymetry and associated hydrodynamics. Waeles et al. [2007] concluded (for a comparable 3D research-model for the Seine River) with the statement that their model is qualitative, rather then quantitative.

From these researches and conclusions, the value to assess the large-scale (general) patterns in the spatial sand-mud distribution, by using a schematized (2DH) tidal inlet system model is given. 
Van Ledden [2003] also adopted this advice in his recommendations.

To assess the large-scale sand-mud patterns, some related observations and hypotheses are needed. Mud particles appear to get transported too less hydrodynamic active areas, as found in both observations (Figure 1) and from physical reasoning (e.g. the formulations for (critical) shear stress combined with the decreasing hydrodynamic activity further into a tidal basin).

Furthermore, Nichols and Boon [1994] introduced a classification of various systems. Two of these are given in Figure 2. Where Figure 2-A (Mobile Bay) shows a mud basin and a margin that is dominated by sand, indicated by case A. Figure 2-B (Arcachon Bay) features sand-rich channels and intertidal areas with an abundant quantity of mud, indicated with case B. This last behavior can also be found in the former Lauwerszee (Figure 1).

As a hypothesis, which is relating this classification to physics, a (relatively) wave- or tide-dominated system can be proposed for case A and B, respectively. This research is aimed at a tidal basin, and the classification of case B is thus further investigated.

\section{METHODS}

A combination of previous studies is used to initiate this research. First, a schematized model of the Amelander inlet system in Delft3D, based on Dissanayake [2011], is used for the spatial model domain, as shown in Figure 3. This Amelander inlet system model is combined with a multi-layered sand-mud Delft3D version, which is set-up during the 'Building with Nature' project (BwN-project) by Deltares. This Delft3D version is a combination of the regular Delft3D-FLOW version [Deltares, 2011] and formulations by Van Ledden [2003], though it also features some (numerical) additions/changes proposed by Deltares.

\section{Schematized Amelander inlet system model}

Based on Dissanayake [2011], a schematized Amelander inlet system model is used (Figure 3). The model is forced by the North Sea tide, which is modelled using the $M_{2}, M_{4}$ and $M_{6}$ tidal components. At this location, the amplitudes of these tidal components are $0.85,0.09$ and 0.06 meter, respectively.

Using the initial sand-only model and the sand-mud version of Delft3D, a stable bathymetry is generated by simulating a 50 -year period of tidally induced forcing (as specified above). This bathymetry (Figure 4-A) is used as the initial bathymetry for all sand-mud simulations, in which mud is supplied by an initial concentration within the water column, initial mud content within the bed and three (continuously supplying) boundary conditions.

\section{Sand-mud version of Delft3D}

When comparing to the regular Delf3D version [Deltares, 2011], the sand-mud mixture version mainly differs in three parts, being (1) the addition of formulations for sand-mud mixtures with cohesive and non-cohesive regimes, (2) the multi-layered bed (in which biological and physical mixing processes between layers is implemented by using internal diffusion) and (3) the implementation of a fluff layer (a thin layer above the bed, in which most mud settles and can be easily eroded again, before actually consolidating into the (more resistant) bed layers below).

The hydrodynamics (like the shallow water equations) and sediment transport equations within the sand-mud mixture version of Delft3D are identical to the regular Delft3D version.

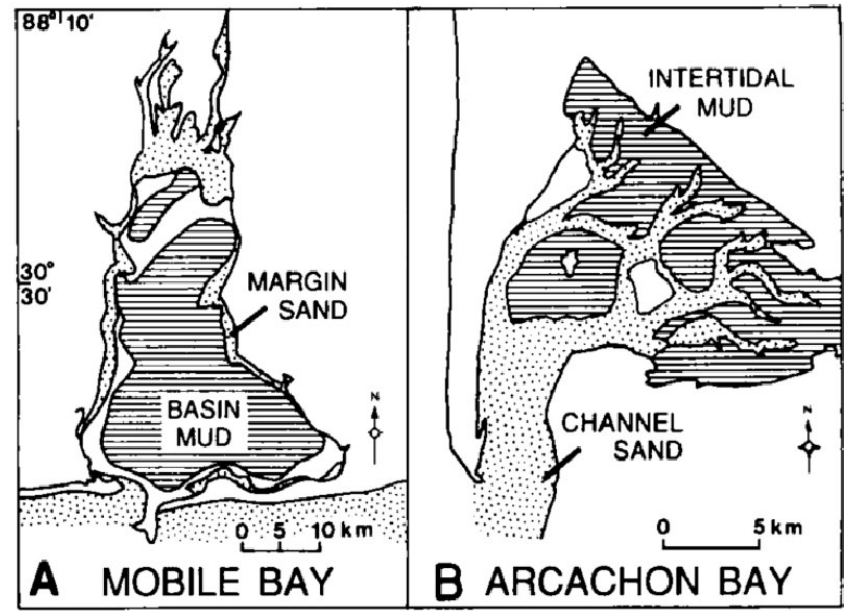

Figure 2. Large-scale sand-mud patterns in basins, with the hypothesis stating that case $A$ is relatively wave-and case $B$ is relatively tidally dominated [after Nichols and Boon, 1994]

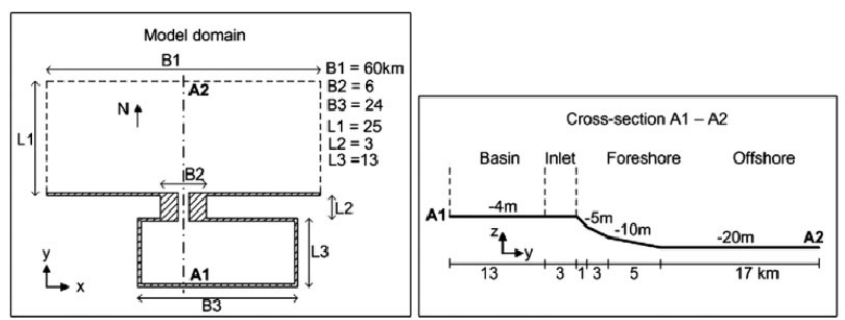

Figure 3. Model domain of schematized Amelander inlet system model, along with cross-section A1-A2 [after Dissanayake, 2011]

Concept of cohesive and non-cohesive sand-mud mixtures

Van Ledden [2003] introduced the concept of formulations for sand-mud mixtures in a cohesive and a non-cohesive regime.

Each mixture features a specific mud content $\left(0 \leq \mathrm{p}_{\mathrm{m}} \leq 1\right)$. By defining a critical mud content $\left(\mathrm{p}_{\mathrm{m}, \mathrm{cr}}\right)$ a sand-mud mixture is either cohesive $\left(\mathrm{p}_{\mathrm{m}, \mathrm{cr}}<\mathrm{p}_{\mathrm{m}} \leq 1\right)$ or non-cohesive $\left(0 \leq \mathrm{p}_{\mathrm{m}}<\mathrm{p}_{\mathrm{m}, \mathrm{cr}}\right)$. Both regimes feature different formulations, as both regimes show different behavior. The formulations enhance the critical bed shear stress for sand-mud mixtures, depending on the mud content. For the full set of equations, one is referred to Van Ledden [2003].

\section{Multi-layered bed and internal diffusion concepts}

A multi-layered bed consists of various layers with different sediment mixtures. Each grid-cell in Delft3D features specific layers. The erosion rate in each cell is based on characteristics in the top layer of that cell. Deposition of a mixture, different to the top layer, results in the generation of a new layer. A maximum number of layers is specified and the final underlayer gains content from layers above, if this maximum number is exceeded.

Due to differences between layers (for instance in $\mathrm{p}_{\mathrm{m}}$ ), mixing could occur due to biological and/or physical processes. This is implemented in the model using internal diffusion between layers.

\section{Fluff layer concept}

When mud settles during gentle hydrodynamic conditions, high concentrations of mud appear near the bed, since the mud particles 
are not easily consolidated in the bed layers. Because of this behavior, the mud particles near the bed appear like in a hindered settling state, making settling, in the underlying bed layer, a slow process. This high concentrated layer (above the bed) is called the fluff layer. Van Kessel et al. [2010] also describes this behavior.

Within the sand-mud version of Delft3D, mud particles first settle to the fluff layer before actually entering the underlying bed layer or re-suspending again into the water column. The critical bed shear stress for erosion is smaller in the fluff layer than in the bed layers. The fluff layer can have significant changes in mud concentration over short timescales (e.g. high concentrations during slack water and low concentrations during ebb- or flood flow), while significant changes for $\mathrm{p}_{\mathrm{m}}$ in the bed occur on much larger timescales, which appears to be in line with observations.

\section{Different model scenarios}

Initially, the model is simulated with tidal- and wind induced forcing to assess the most realistic scenario, called the reference scenario. Furthermore, scenarios with an increase and decrease in tidal amplitude (and thus tidal prism $\Omega$ ) are simulated.

Areas within the tidal basin without any morphological influence (Southwest and Southeast areas) were stripped from the spatial domain, to prevent model artifacts to occur (Figure 4-A).

\section{Verification of Delft3D sand-mud version}

Before executing the scenarios, verification of the Delft3D sand-mud model is preferred, as changes compared to the original concept by Van Ledden [2003] were made.

The model appears to resemble previous models, as indicated by Scheel [2012]. The model is therefore considered verified.

\section{RESULTS}

Model scenarios were run with a morphological time period of 3 months (also hydrodynamic, as Morfac = 1), with mud concentrations at the boundaries running from $10 \mathrm{mg} / \mathrm{l}$ (at the North Sea) to $30 \mathrm{mg} / 1$ (near the coasts of the Frisian islands). The initial mud content in the bed is $5 \%$ and the water column initially features $10 \mathrm{mg} / \mathrm{l}$ dissolved mud particles throughout the domain.

\section{Reference scenario}

The reference scenario, using realistic tide and average wind conditions, shows realistic results, as observed in the field. With mud abundant on tidal flats and near tidal basin boundaries, while absent in (tidal) channels (see Figure 4-B). Apart from the general sand-mud segregation patterns, the values of mud content and concentrations in the water column, within these patterns, also show realistic values, typical for basins in the Dutch Wadden Sea.

\section{Large tidal range scenario}

This large tide scenario is, apart from the tidal amplitudes, which are twice as high, an exact copy of the reference scenario. The behavior, observed by Nichols and Boon [1994] in Arcachon Bay (Figure 2-B) and by Van Straaten and Kuenen [1957] in the Lauwerszee (Figure 1), is reproduced and, compared to the reference scenario, enhanced (Figure 4-C). This observation supports the hypothesis on tidal dominated basins (as the relative tidal dominance increased compared to the reference scenario).

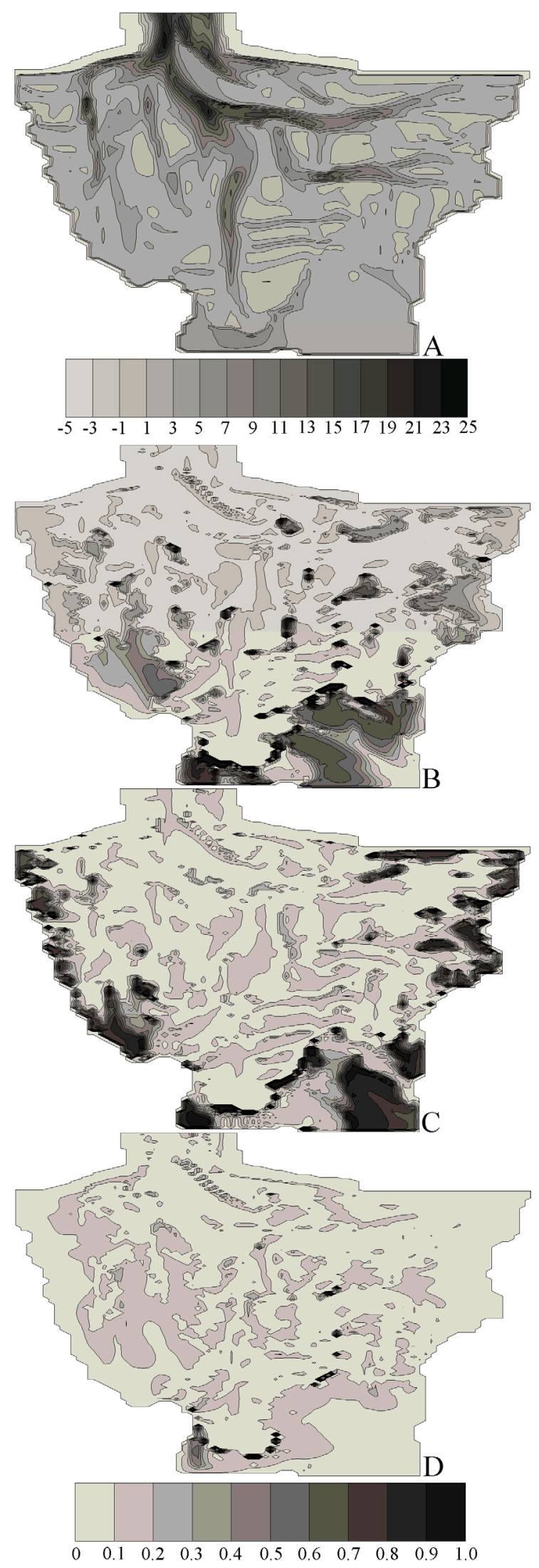

Figure 4. (A) Model bathymetry (depth) and mud content in top layer for scenarios $(B)$ reference, $(C)$ large tide and $(D)$ small tide 


\section{Small tidal range scenario}

The small tide scenario is an exact copy of the reference scenario, though it features tides with halved tidal amplitudes. As observations no longer show abundance of mud on tidal flats and model boundaries, the expected behavior for a tidal dominated system is no longer met. From the observations, it appears that the tidal dominance is diminishing, also diminishing the associated characteristics. This is again in line with the hypothesis.

\section{ANALYSIS}

First, the total mud transport to and through specific sections within the tidal basin is tracked, as mud content observations in the top layer (Figure 4) doesn't provide total transports (content in underlayers is not visible in Figure 4). Different runs are thus compared in a more quantitative manner, rather then qualitative.

Second, the 'hypsolaspy' curve is introduced. This curve relates the mud content to depth (comparable to a hypsometry curve) and therefore indicates the relation between these variables.

Finally, a relation between occurring shear stress and mud content is visualized (using a scatterplot).

\section{Mud transport through the tidal basin}

By dividing the tidal basin in equidistant sections from north to south (section A to H), Scheel [2012], the mud transport through the tidal basin for the different scenarios is compared.

Looking at Figure 5, the reference scenario shows expected behavior, with mud transported to the southern (boundary) sections (where most tidal flats are found), with mud coming from the North (where mainly channels are found).

The large tide scenario also shows this behavior, though with much larger magnitude. While the low tide scenario supports the previous statements, though it also shows the behavior from the other scenarios on a much smaller scale.

Furthermore, note that the turning point for ex- and import is moving inwards with increasing tidal amplitudes.

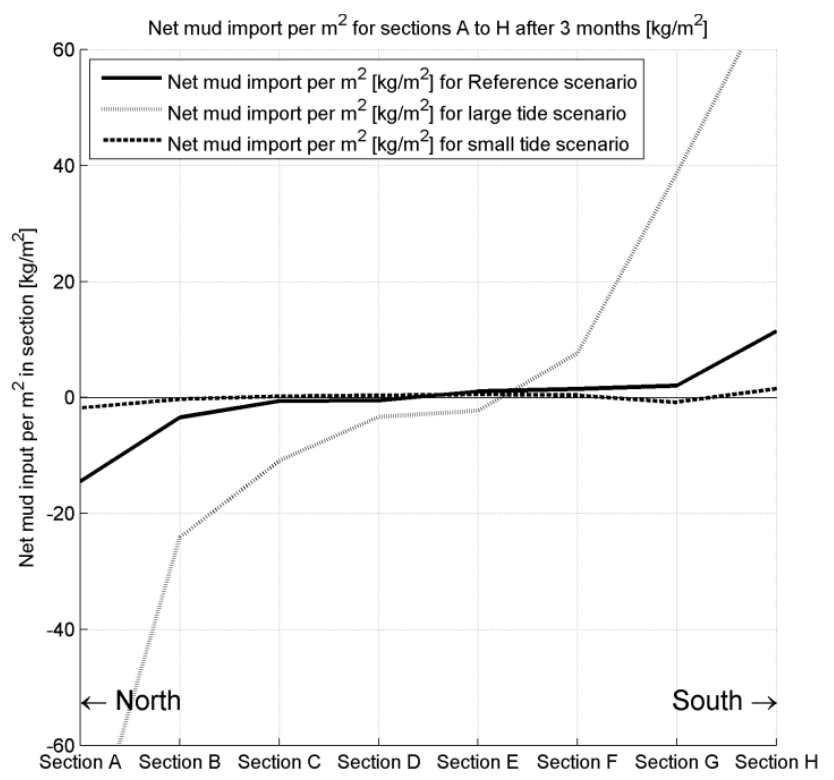

Figure 5. Average mud import $\left[\mathrm{kg} / \mathrm{m}^{2}\right]$ per (equidistant) section, with sections running from North (section A) to South (section H)
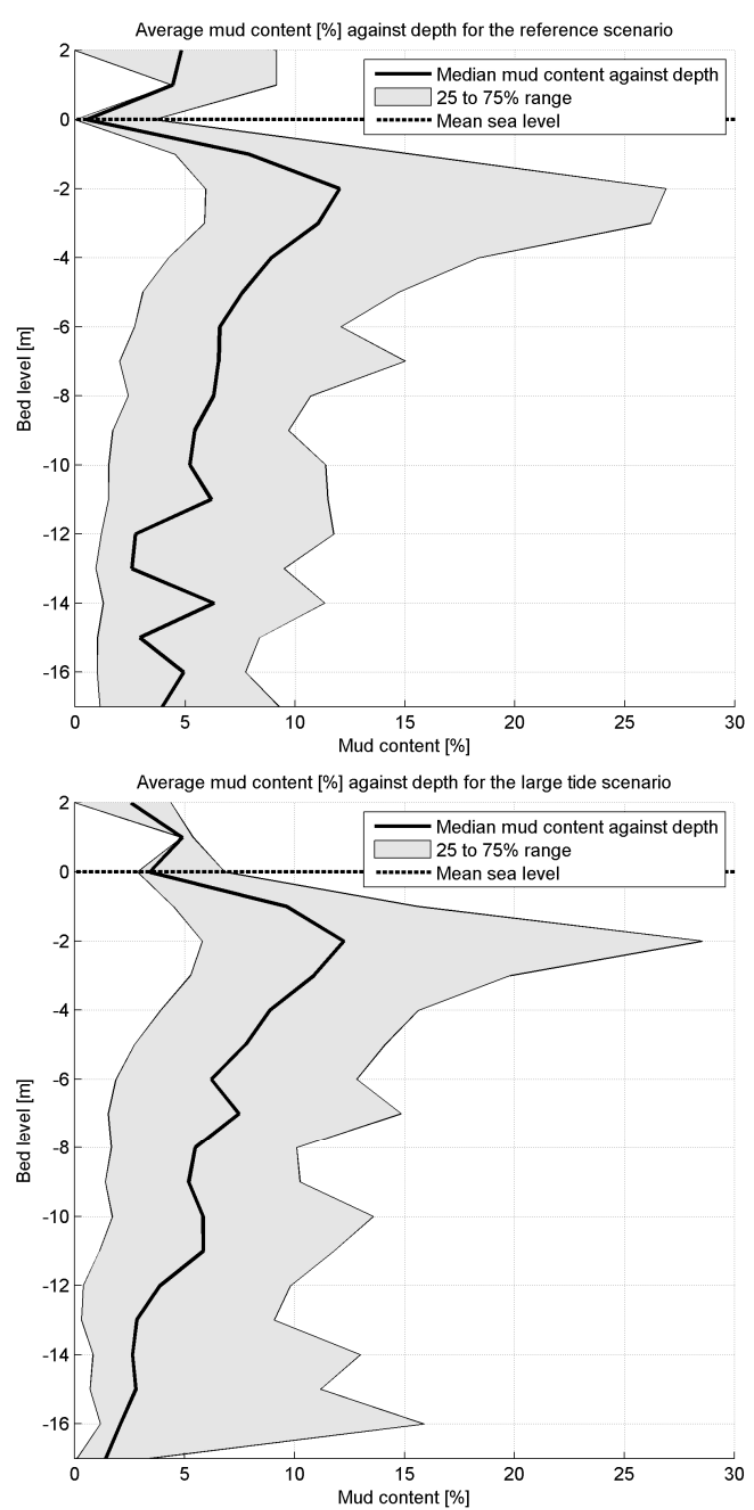

Average mud content [\%] against depth for the small tide scenario

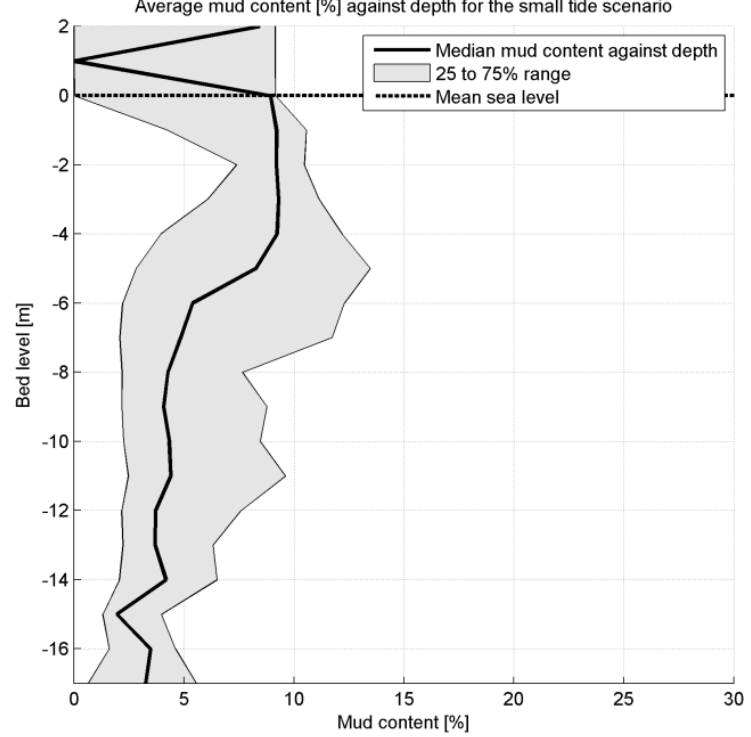

Figure 6. Hypsolaspy curves for all (indicated) scenarios 


\section{'Hypsolaspy' curves}

Figure 6 introduces hypsolaspy curves for all scenarios. With MSL at 0 , the reference situation shows an increase in mud content for shallower areas. This result is as expected, as shallower areas are found further into the tidal basin, these areas are less hydrodynamically active and mud particles are allowed to settle in these regions.

When looking at the large tide scenario, the behavior is comparable to the reference situation, though mud content is smaller in the deeper parts (channels) in the system. While the small tide scenario shows smaller differences, the mud content in shallow areas is still larger compared to the deeper areas.

\section{Occurring shear stress against mud content}

By relating the occurring bed shear stress to the mud content for all grid-cells in the tidal basin, a scatterplot (Figure 7) can be constructed. By normalizing the bed shear stress with the critical bed shear stress (for $\mathrm{p}_{\mathrm{m}}=1$, which is the maximal critical shear stress) an interesting distinction can be made. It appears that cohesive mixtures are mainly present when the occurring shear stress is below the critical shear stress. This implies that more mud (cohesive mixtures) is found in shallow areas (e.g. tidal flats), as shear stresses are smaller in these areas Scheel [2012]. Van Ledden [2003] also observed this behavior.

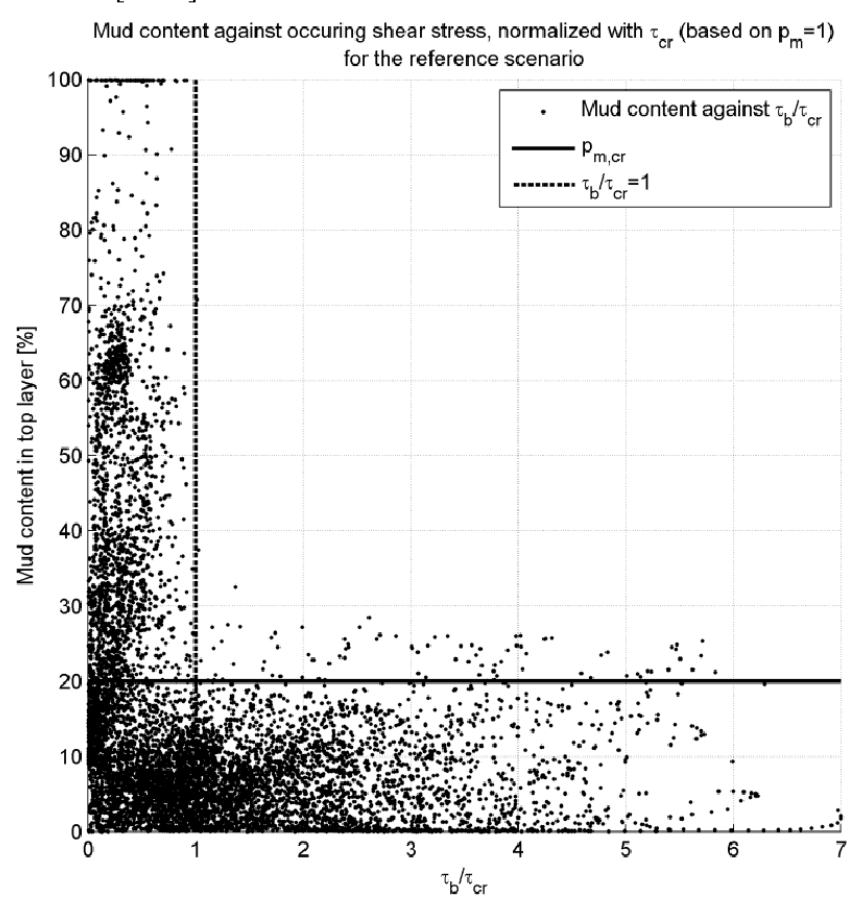

Figure 7. Mud content against occurring bed shear stress (normalized with critical shear stress for $p_{m}=1$ )

\section{DISCUSSION}

In this contribution, research on large-scale sand-mud segregation patterns in a tidal dominated basin is combined with a hypothesis related to tidal- and wave-dominated systems and their relation towards these patterns. While the assessment of the tidally dominated case was considered in this research, the complete assessment of the hypothesis, which requires a wave-dominated system (with wave implementation), is attempted in overlapping research [Scheel, 2012].

Large-scale patterns can be assessed much easier with a schematized (2DH) model, just like the approach by Dissanayake [2011]. Though, it will not reproduce exact field observations.

\section{CONCLUSIONS}

This contribution is one of the first to apply the Delft3D version with sand-mud mixtures, and therefore puts it to the test. It appears a well applicable model, solidly based on work by Van Ledden [2003].

A schematized (2DH) model is an advantage for assessing general sand-mud segregation patterns, as observations in the field (e.g. abundant mud in tidal flats and scarce amount of mud in tidal channels) can successfully be reproduced.

Tidally dominated basins (tidal basins) feature mud at intertidal areas (and at tidal basin land-boundaries) and lack mud in tidal channels. These observations are made due to the tidal dominance, as hypothesized. The diminishing tidal (hydrodynamic) influence into the basin is highly responsible for this outcome.

\section{ACKNOWLEDGEMENT}

Sincere thanks goes out to Deltares, in particular Thijs van Kessel, for providing a workplace, cluster and the sand-mud version of Delft3D (which is currently under development) free of charge. Furthermore Royal Haskoning and Delft University of Technology are thanked for their workplaces, help and support during the entire (overlapping) M.Sc. research [Scheel, 2012].

\section{REFERENCES}

Deltares (2011), Delft3D-FLOW, Simulation of multi-dimensional hydrodynamic flows and transport phenomena, including sediments, user manual, version 3.15, $674 \mathrm{p}$.

Dissanayake, D.M.P.K. (2011), Modelling morphological response of large tidal inlet systems to sea level rise. CRC Press/Balkema, Leiden, $178 \mathrm{p}$.

Van Ledden, M. (2003), Sand-mud segregation in estuaries and tidal basins, PhD thesis, Repository TU Delft, $221 \mathrm{p}$.

Van Ledden, M., Z.B. Wang, J.C. Winterwerp, and H. de Vriend (2004), Sand-mud morphodynamics in a short tidal basin, Springer, Ocean Dynamics, Vol. 54, pp. 385-391.

Nichols, M., and J.D. Boon (1994), Sediment transport processes in coastal lagoons, Elsevier Science Publishers, Oceanography Series, Vol. 60, pp. 157-219.

Scheel, F., Simulating the large-scale spatial sand-mud distribution in a schematized process-based tidal inlet system model, M.Sc. thesis, Repository TU Delft, Forthcoming 2012.

Van Straaten, L.M.J.U., and P.H. Kuenen (1957), Accumulation of fine grained sediments in the Dutch Wadden Sea, Lingua Terrae, Geologie en Mijnbouw 19, pp. 329-354.

Waeles, B., P. Le Hir, P. Lesueur, and N. Delsinne (2007), Modelling sand/mud transport and morphodynamics in the Seine River mouth (France): an attempt using a process-based approach, Springer, Hydrobiologia, Vol. 588, no. 1, pp. 69-82.

Van Kessel, T., J.C. Winterwerp, B.C. van Prooijen, M. van Ledden and W. Borst (2010), Modelling the seasonal dynamics of SPM with a simple algorithm for the buffering of fines in a sandy seabed, Continental Shelf Research 31, pp. 124-134. 